\title{
Topology Optimization of Excavator Bucket Link
}

\author{
R. B. Sarode, S. S. Sarawade \\ (Department of Mechanical Engineering, M.E.S. College of Engineering S. P. Pune University, India)
}

\begin{abstract}
Heavy duty excavators are operated during the excavation process the unknown resistive forces offered by the terrain to the bucket teeth is transformed to the other parts via bucket linkage. Excessive amount of these forces adversely affected on the bucket link therefore the optimization of bucket linkage is done on the maximum breakout forces which are exerted on it during operation. Thus, it is very much necessary to provide not only a better design of parts having maximum reliability but also of minimum weight and keeping design safe under all loading conditions. In this paper, the weight optimization is done around $7.34 \mathrm{~kg}$ with increase in $5.6 \%$ in stress levels and $12.2 \%$ in deformation but this increment in stress as well as deformation of bucket linkage is within permissible limit. The optimization is performed using on Optistruct and the $3 D$ model of a bucket link is generated in Catia V5. Meshing is carried out in Hypermesh and Ansys R15.0 is used for preprocessing, solutions, post processing. According to Optistruct results the material is removed from the regions where there is less stress concentration. After achieving desirable results, the optimized model of bucket link is manufactured, then testing of bucket link is performed using Universal Testing Machine.
\end{abstract}

Keywords: Excavator bucket link, Scale down model, Similitude, Topology optimization

\section{Introduction}

Excavator bucket linkage is the most important part in the mechanism by which all the digging forces are transmitted form ground to the boom via bucket link. A pivotal boom of an excavator is attached to the pivotal arm. The positions of the boom relative to the vehicle and the arm relative to the boom are controlled by hydraulic cylinders. The one end of idler link or bucket link is directly pin jointed to bucket and at the other end to intermediate link and hydraulic rams as shown in Fig 1. This is done to avoid the bending of the idler link due to, 1 . The force from the bucket cylinder piston rod directly transfers to the bucket link. 2 . The width of the bucket link is less compared to intermediate links. The generalized mathematical model of breakout force of the proposed excavator is presented but for static analysis, one of the forms of the mechanism has to be selected first for which the analysis is to be done. From every one of the forms, the greatest breakout force condition is the most critical one as it creates the maximum breakout or digging forces and it can be utilized as boundary conditions to conduct a static finite element analysis of the excavator bucket linkage. The breakout forces have been taken for the boundary conditions for the static finite element analysis because the resistive digging forces are smaller than the breakout forces produced by all components of mechanism [1]. The resistive forces generated by the terrain during excavation process and the digging forces offered by the actuators of excavator are more prominent than the resistive forces and they are responsible to dig the terrain. So that, it is very vital to test the bucket linkage used in presented model of excavator for the stresses induced during the excavation operations so the optimized model of excavator bucket linkage is tested for the compressive strength [2]. In this paper the alternate design is find out which will reduce in weight and it can withstand high level of stresses that are induced in the bucket link. A 3D model of a bucket link is generated in Catia V5. Meshing is carried out in Hypermesh and Ansys R15.0 is used for solution. The optimization is carried out in Optistruct. According to Optistruct results topology optimization will be carried out by removing the material from the regions where there is less stress concentration. After achieving desirable results, the optimized model of bucket link will be manufactured then experimental testing of bucket link will be done using Universal Testing Machine.

Patel, et. al. [1], performed the static force analysis of the backhoe excavator for the condition in which the mechanism produces the maximum breakout force. One configuration of the mechanism is decided first for which the mechanism produces maximum breakout force. From all the configurations the maximum breakout force condition is the most critical one as it produces the highest breakout force and for this condition the force analysis is to be carried out. Patel, et. al. [2], weight optimization of backhoe excavator attachment by using FEA approach by trial and error method. Shape and weight optimization is carried out and results are compared which shows identical results. Mishra, et. al. [3], analyzed the force calculation of excavator bucket and calculation of excavator bucket capacity has been calculated and the breakout force is determined. The SAE provides improved bucket geometry for efficient digging and loading of material along with heavy duty robust 
construction for increased strength and durability. Mehta, et. al [4], analyzed the existing design and redesign the parts of attachments which are failing under the given operating conditions due to the varying stresses induced in the attachment. Use of a finite element analysis to understand the behavior of the structure which provides specified breakout force Dave, et. al [5], the forces acting on each part such as bucket, arm, boom of mechanism are obtained by static force analysis and these forces are used as boundary conditions for finite element analysis. After interpreting Ansys results stresses in bucket, boom, arm are found to be within allowable stress limit and design modifications are done like stiffener is added on inner as well as outer sides, shape of mounting plates is changed are made to minimize the weight of designed component. Dhawale, et. al [6], this paper is review of the different analysis done on the components of excavator arm and there are various forces affects the components of excavator arm. The two important factors considered during designing an excavator arm are productivity and fuel consumption. Also the bucket volume is increased to compensate for the loss in production due to the reduction in digging force. Increased in bucket volume will also increase the amount material to be fed in the bucket. The excavator mechanism must work reliably under unpredictable working conditions. thus it is very much necessary for the designers to provide not only an equipment of maximum reliability but also of minimum weight and cost, keeping design safe under all loading conditions.

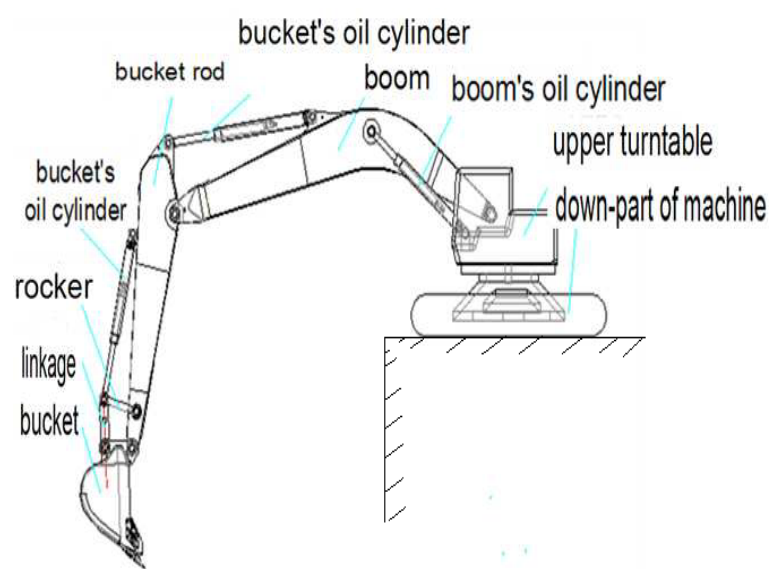

Fig.1. Typical hydraulic excavator

\section{Problem Defination}

The unknown resistive forces offered by the terrain to the bucket teeth are transformed to the other parts via bucket link during the excavation operation. The maximum breakout force condition is considered at which the maximum force is produced while digging and transmitted via bucket link which is very worst of all conditions. Excessive amount of these forces adversely affect the bucket link and even it fails during excavation operation. Therefore, these parts must be strong enough to withstand working conditions of the excavator. Normally, the excavators are working under cyclic motion during excavation operations. That high level of stresses can cause the crack in bucket link of excavators and it will adversely affected on productivity of machine. Now a day, weight is major concern while designing the machine components. Therefore, the main purpose of this paper to reduce the weight of bucket linkage without affecting it strength by proper optimization technique which also reduces the overall cost for smoothing the performance of machine.

\section{Calculation of Static Forces on Bucket Link}

In this section, the static force analysis of the excavator is explained for the condition at which the mechanism produces the highest breakout force. In the static analysis one configuration of the mechanism has to be selected first for which the analysis is to be performed. The finite element analysis is accomplished for the position and orientation of the mechanism which all components deliver the highest breakout forces. The configuration at which all the components of excavator are generated the maximum breakout force is demonstrated in Fig 2. In this chapter the forces acting with the directions and magnitudes on bucket linkage and excavator bucket are described in the free body diagram which helps to the determination of forces on bucket linkage. It is observed that, in the maximum breakout force configuration at point $A_{1}$ the reaction force exerted due to the breakout force $\left(F_{B}\right)$ acts at an angle of $38.23^{\circ}$ on the bucket tooth of an excavator which is shown in the Fig.2, According to SAE the maximum breakout force is considered to be $54 \mathrm{KN}$ which is acting at a joint $A_{1}[7]$. 


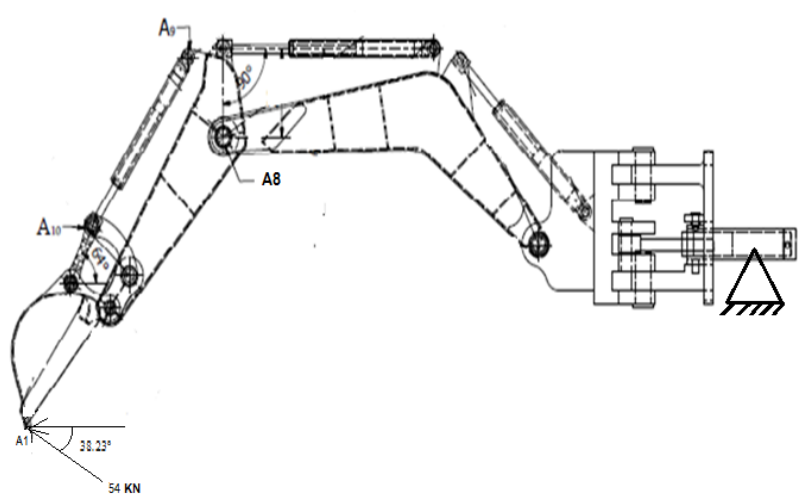

Fig.2. Maximum breakout force configurations

As shown in Fig.3, the forces acting on bucket link are calculated by resolving forces in the $\mathrm{X}$ and $\mathrm{Y}$ directions respectively.

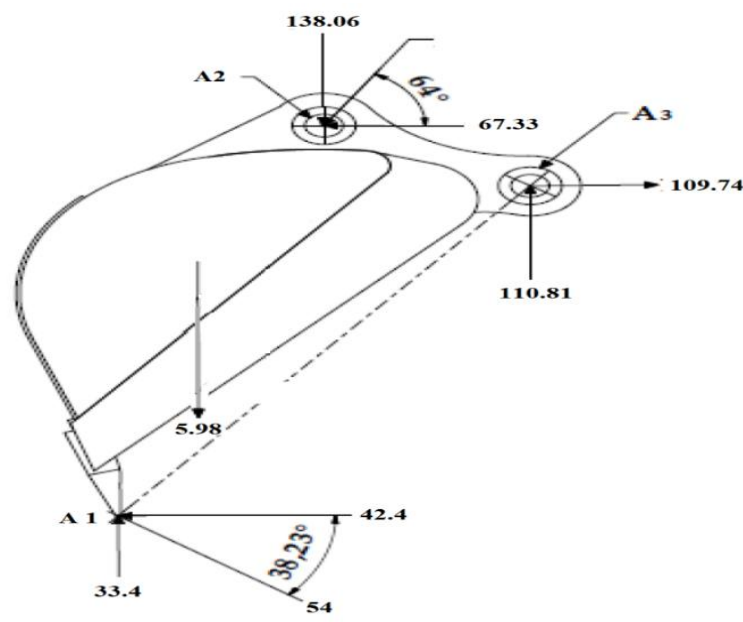

Fig.3. Free body diagram of bucket

The horizontal and vertical component of reaction force $54 \mathrm{KN}$ at point $A_{1}$ is represented using eq. (1) and (2), as $-42.4 \mathrm{KN}$, and $33.4 \mathrm{KN}$ respectively.

$$
\begin{aligned}
& F_{1 H}=F_{B} \cdot \cos \alpha \\
& F_{1 V}=F_{B} \cdot \sin \alpha
\end{aligned}
$$

Where, $\alpha$ is the angle between the highest breakout force exerted on the bucket tool tip and the horizontal X axis at an angle of $38.23^{\circ}$ at joint $A_{1}$ as shown in Fig.3, Now consider the bucket in equilibrium condition i.e. $\Sigma M_{A 3}=0$ and take the moment about bucket pivot point $A_{3}$.

Nomenclature

$$
F_{1} \cdot L_{1}-F c g . L c g=F_{2} \cdot L_{2}
$$

$F_{1}=54 \mathrm{KN}$, the force exerted at bucket tool tip at point $A_{1}$ when the bucket reaches to the ground in the highest breakout force configuration which is equal to the breakout force $F_{B}$.

$L_{1}=1620 \mathrm{~mm}$, the perpendicular distance between the tip of the bucket tool $A_{1}$ and the bucket pivot point $A_{3}$. $F c g=5.98 \mathrm{KN}$, the gravitational force acting on bucket.

$L c g=660 \mathrm{~mm}$, the perpendicular distance between center of gravity of the bucket to the bucket pivot point $A_{3}$

$F_{2}=$ The force exerting on the pivot point $A_{2}$ of the bucket link which can be calculated using eq. (3) and it is acting at an angle $\left(\beta=64^{\circ}\right)$. 
$L_{2}=543 \mathrm{~mm}$, the perpendicular distance between the bucket pivot point $A_{2}$ to the bucket linkage pivot point on bucket.

By substituting all values in eq. (3) the resultant force $F_{2}=153.83 \mathrm{KN}$.

The resultant force $F_{2}$ can be resolved in $\mathrm{X}$ and $\mathrm{Y}$ directions respectively by using eqs. (4) and (5).

$$
\begin{aligned}
& F_{2 H}=F_{2} \cdot \cos \beta \\
& F_{2 v}=F_{2} \cdot \sin \beta
\end{aligned}
$$

The eqs. (4) and (5) gives,

$$
\begin{aligned}
& F_{2 H}=-67.33 \mathrm{KN} \text { and } F_{2 V}=-138.06 \mathrm{KN} \\
& F_{3 H}=109.74 \mathrm{KN} \text { and } F_{3 V}=110.81 \mathrm{KN} \text { respectively. }
\end{aligned}
$$

The negative sign shows that the orientation of horizontal component of the load exerted in the leftward direction and vertical component of the force in the downward direction.

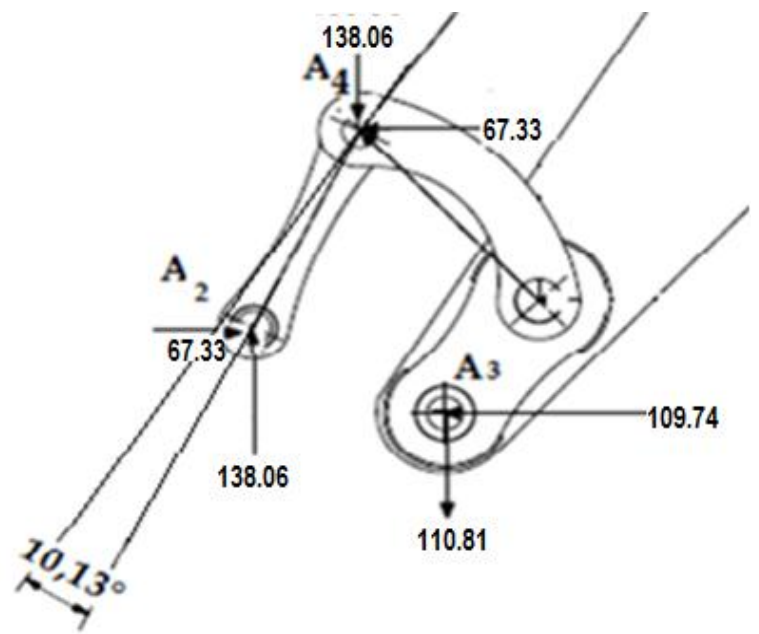

Fig.4. Free body diagram of bucket link

Therefore, the condition at which mechanism produces the maximum breakout force, the forces acting on bucket link are calculated. The forces on joint A4 are exactly equal and opposite forces acting on joint A2.

\subsection{Design stress for excavator bucket link.}

As shown in Fig.4, the joint A4 is fixed during the analysis the $153.83 \mathrm{KN}$ force is applied at joint A2, therefore the bucket link is subjected to pure compression at the maximum breakout force condition.

Design stress for a ductile materials can estimated as,

$$
\sigma_{V M} \leq \frac{\sigma_{y}}{\text { Factor of safety }}
$$

The bucket link is made up of steel IS2062 material having yield stress value $250 \mathrm{MPa}$, by taking factor of safety as 2, the yield stress value from eq.[6] is $\sigma_{y}=125 \mathrm{MPa}$. It clearly indicates that $\left[\sigma_{V M} \leq \sigma_{y}\right.$ ], so the design is safe as the Von-Mises stress of optimized bucket link should be less than $125 \mathrm{MPa}$.

\section{Finite Element Analysis}

The dimensions for excavator bucket link were measeured from site of Caterpillar 320dl model. These dimensions taken from the actual model of excavator were used for 3D modelling of bucket link.

\subsection{Meshing}

CAD model as shown in Fig.5 is generated in part design module of Catia V5. This parametric generation of drawings will help to get the dimensions useful in forces calculations in static loading conditions. 
IOSR Journal of Mechanical and Civil Engineering (IOSR-JMCE)

e-ISSN: 2278-1684,p-ISSN: 2320-334X

PP. 12-26

www.iosrjournals.org

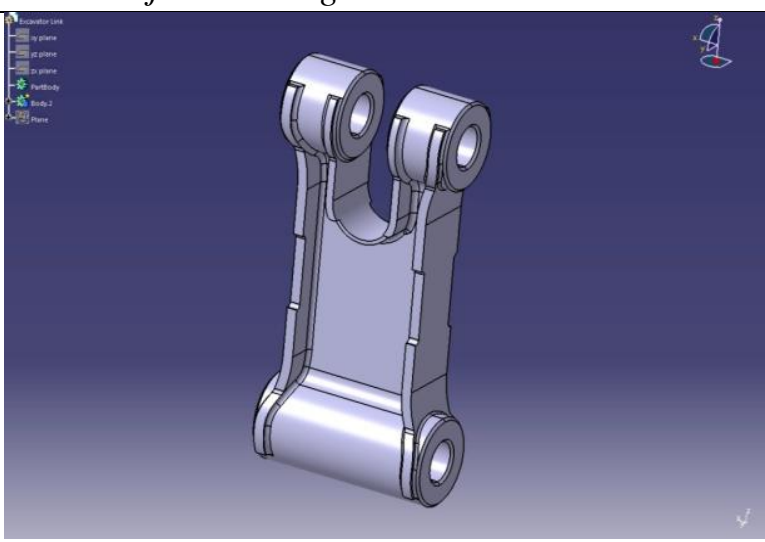

Fig.5. CAD model of existing bucket link drawn in CATIA V5.

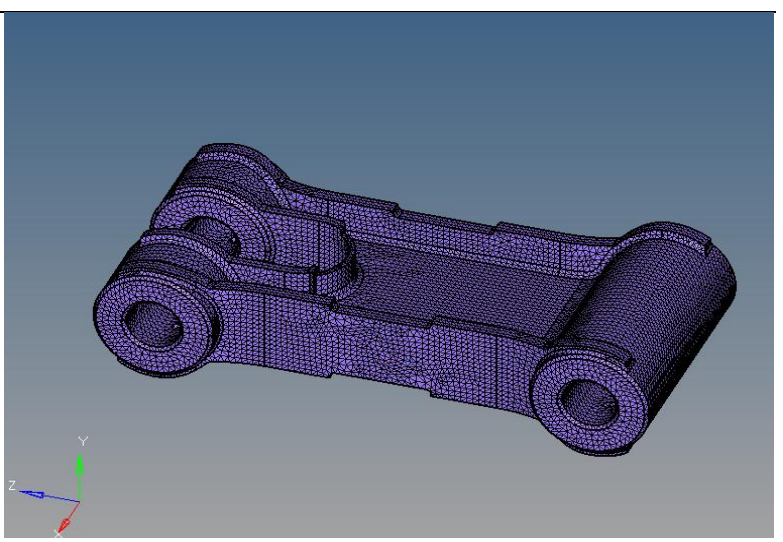

Fig.6. Meshing of bucket link

Fig.6 shows the meshed model of bucket link and the Table.1 shows the details of parameters required for meshing.

Table 1 Meshing parameters for existing bucket link

\begin{tabular}{|l|l|}
\hline Type of element & Tetra-hedral \\
\hline Number of nodes & 26917 \\
\hline Number of elements & 109778 \\
\hline Element size & $4 \mathrm{~mm}$ \\
\hline
\end{tabular}

\subsection{Boundary conditions}

After meshing is completed boundary conditions are applied. These boundary conditions are the reference points for calculating the results of analysis. Here the different load steps are created which are to be applied during analysis. The material properties such as density, modulus of elasticity, Poisson's ratio are assigned to the elements. After the completion of process model is exported to the solver.

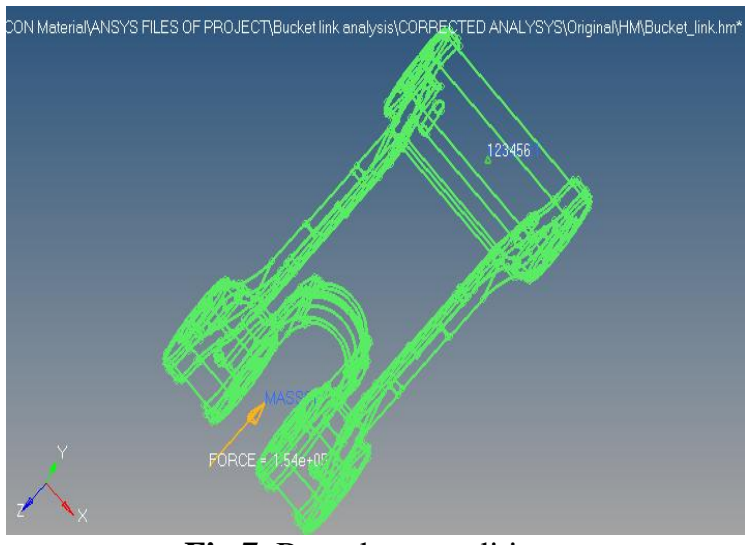

Fig.7. Boundary conditions

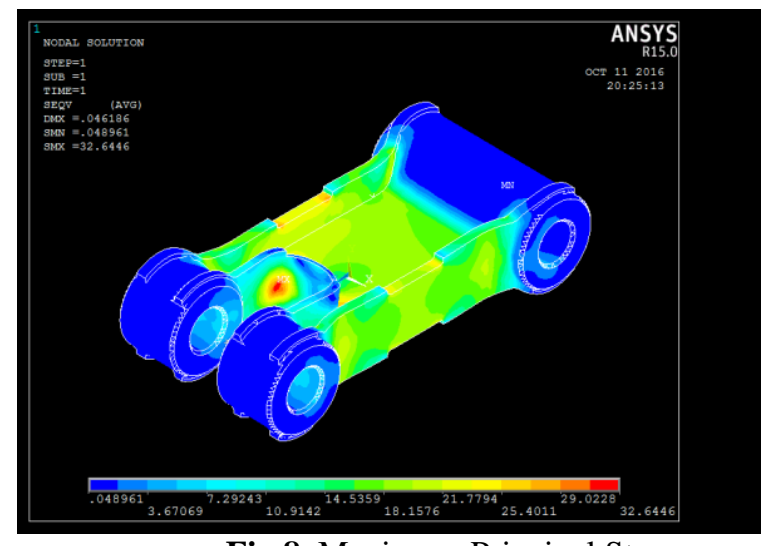

Fig.8. Maximum Principal Stress

As shown in Fig.7, the joint A4 is fixed during the analysis and horizontal and vertical loads are applied at joint $\mathrm{A} 2$ as $67 \mathrm{KN}$ and $138.23 \mathrm{KN}$ respectively.

4.3 Mechanical properties used for bucket link

Table 2 Mechanical properties of IS2062 [1]

\begin{tabular}{|c|c|}
\hline Modulus of elasticity & $200 \mathrm{GPa}$ \\
\hline Poisson's ratio & 0.3 \\
\hline Density & $7850 \mathrm{~kg} / \mathrm{m}^{3}$ \\
\hline Yield tensile strength & $250 \mathrm{MPa}$ \\
\hline Ultimate tensile strength & $410 \mathrm{MPa}$ \\
\hline
\end{tabular}


Material selection for bucket link - The bucket link is usually made of the material IS2062. The mechanical properties of IS2062 are mostly used for the different parts of the excavators such as collars and bushes and bucket links. IS2062 is a high tensile strength steel.

\subsection{Analysis}

Meshed and boundary condition applied model is imported to the solver. Software first calculates the deflection with respect to the boundary conditions applied. Then on the basis of deflection it calculates strain. Once the strain is calculated the modulus of elasticity is known then the stress values are calculated.

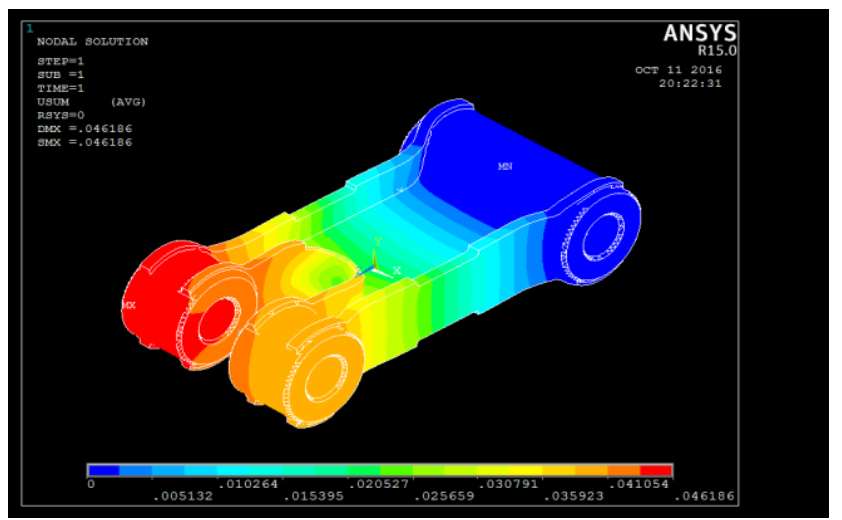

Fig.9. Maximum Deformation

Fig.8 and Fig.9 shows the stress induced in bucket link is $32.64 \mathrm{MPa}$ and deformation of link as $0.046186 \mathrm{~mm}$ which is well below critical value $125 \mathrm{MPa}$. Hence, the design is safe.

\section{Optimization}

Weight reduction is done using topology optimization by meeting the strength, safety factor targets and the corresponding weight reduction is analyzed

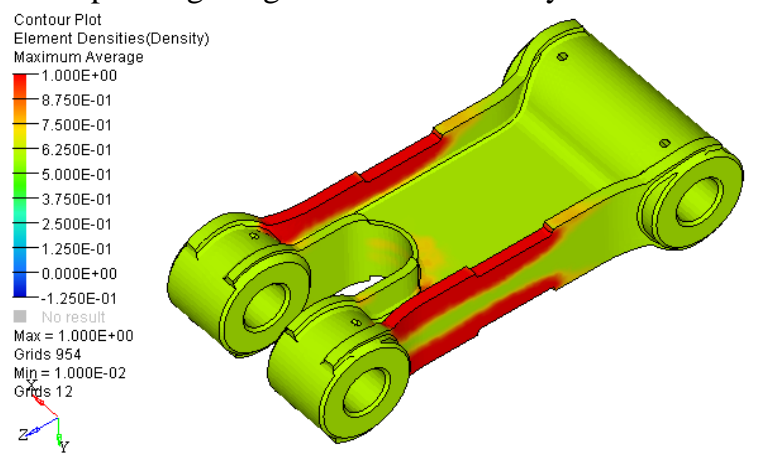

Fig .10: First iteration

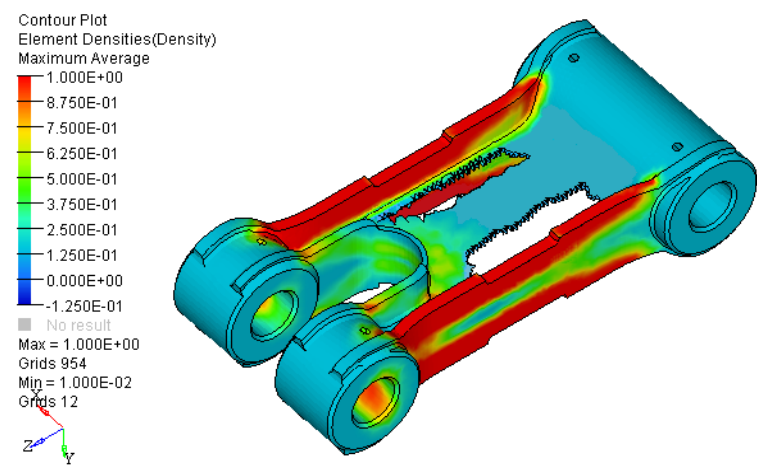

Fig. 11: Final iteration for optimization

From the iterations shown in Fig.10 and Fig.11 of optimization process, it is observed that the material is removed by Optistruct in the mid rectangular section. Therefore as shown Fig.12 in CAD model of bucket link the material is removed from the two elongated holes measuring $150 \mathrm{~mm}$ length by $15 \mathrm{~mm}$ radius from the rectangular section of bucket link. Due to functional constraints and the loading conditions the material can not be removed from both end pin connectors of the bucket link.

\subsection{First iteration}

In the first iteration two elongated holes measuring $150 \mathrm{~mm}$ length by $15 \mathrm{~mm}$ radius has been removed from the rectangular section of bucket link as shown in Fig.12 and Fig.13 and the Table 3 shows the details of parameters required for meshing. Fig.14 and Fig.15 shows the stress induced in bucket link is $46.50 \mathrm{~N} / \mathrm{mm} 2$ which is below the critical value of $125 \mathrm{~N} / \mathrm{mm} 2$ and the deformation of bucket link is $0.0503 \mathrm{~mm}$. Hence, the design is safe and according to CAD model the mass of bucket link is $112.2 \mathrm{Kg}$. 


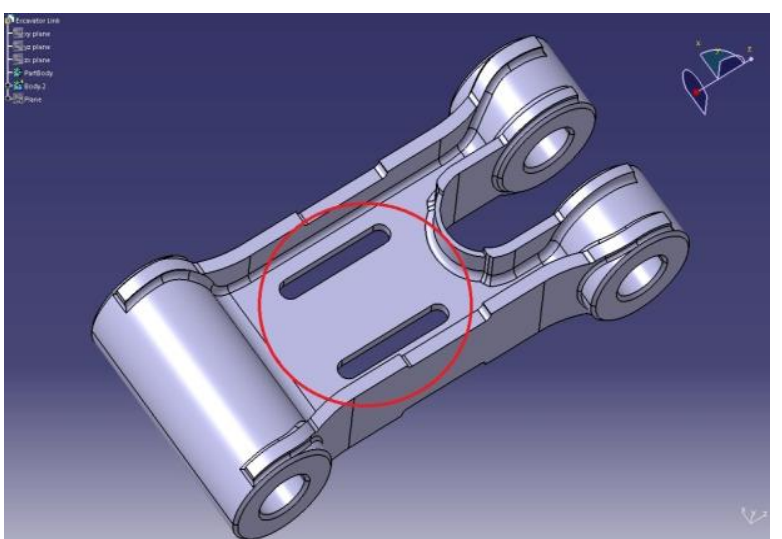

Fig. 12: CAD model of bucket link

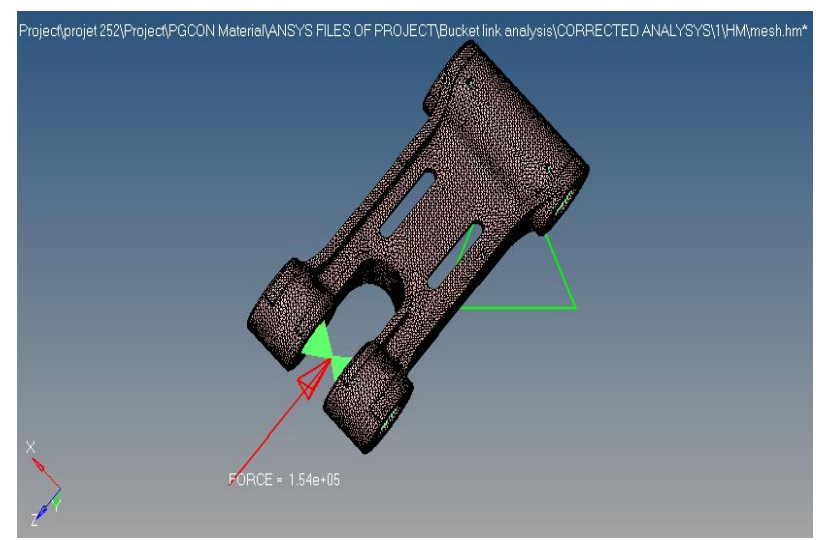

Fig. 13: Meshed model of bucket link for first iteration

Table 3 Meshing parameters for first iteration

\begin{tabular}{|l|l|}
\hline Type of element & Tetra-hedral \\
\hline Number of nodes & 27040 \\
\hline Number of elements & 110080 \\
\hline Element size & $2 \mathrm{~mm}$ \\
\hline
\end{tabular}

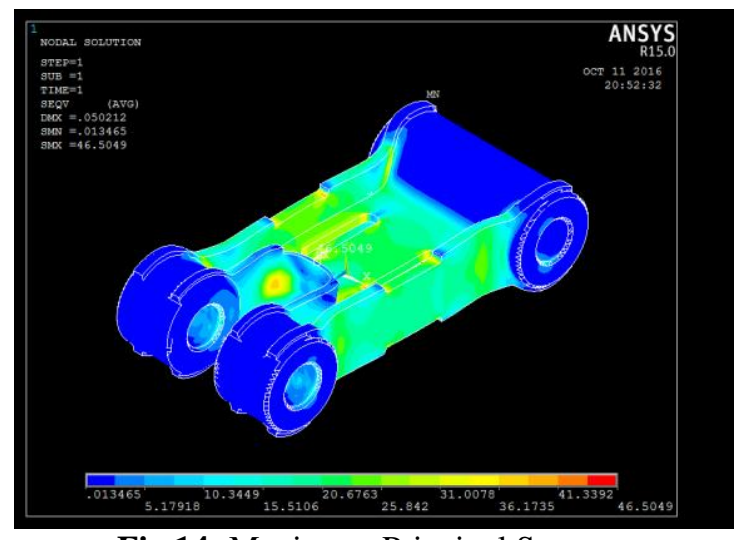

Fig.14: Maximum Principal Stress

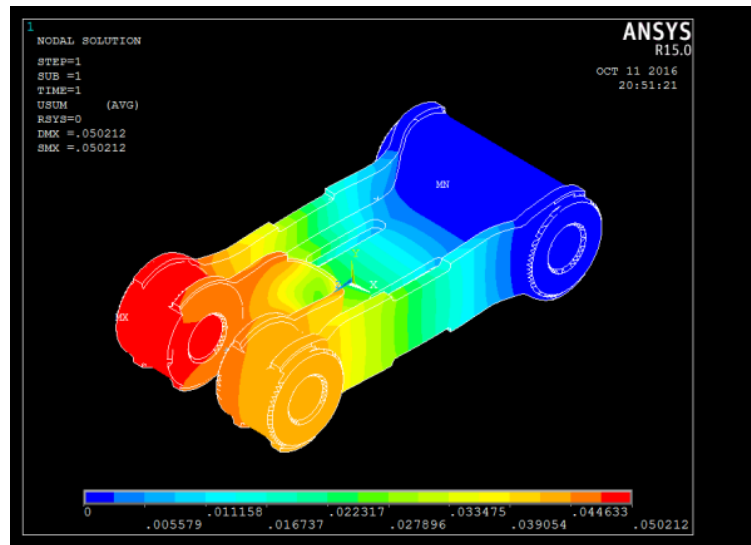

Fig.15: Maximum deformation

\subsection{Second iteration}

After first iteration, the thickness of the rectangular section of bucket link is reduced to $13 \mathrm{~mm}$ from $15 \mathrm{~mm}$ thickness. As shown in Fig.16 and Fig.17 shows the CAD model and meshed model of bucket link and the Table 4 shows the details of parameters required for meshing.

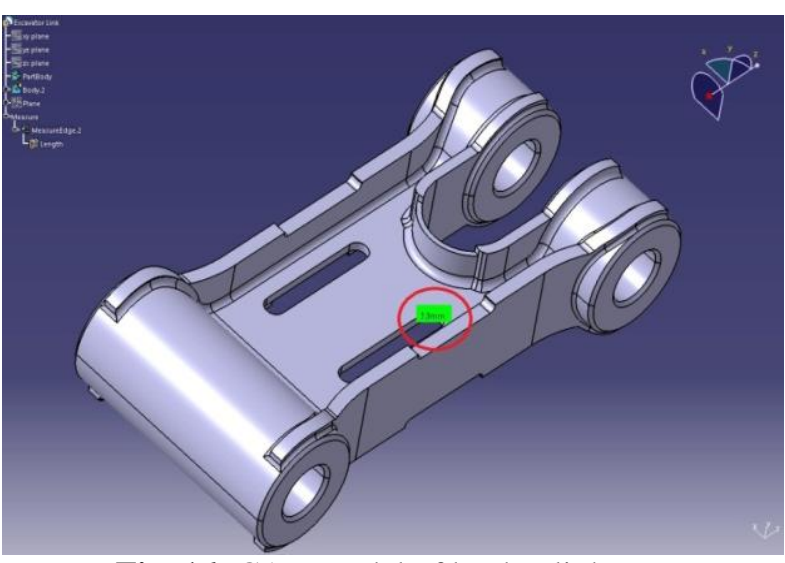

Fig. 16: CAD model of bucket link

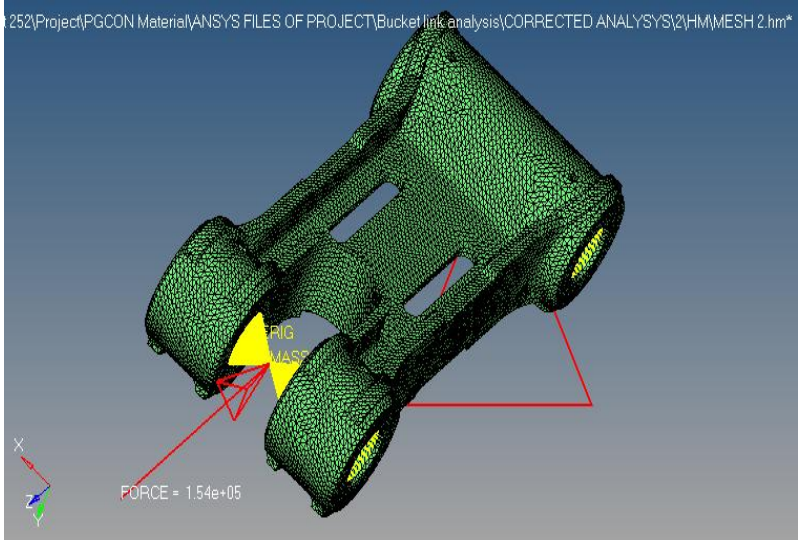

Fig. 17: Meshed model of bucket link for second iteration

Table 4 Meshing parameters for second iteration

6th National Conference RDME 2017, 17th- 18th March 2017. M.E.S. College of Engineering, Pune. 411001 


\begin{tabular}{|l|l|}
\hline Type of element & Tetra-hedral \\
\hline Number of nodes & 26747 \\
\hline Number of elements & 108449 \\
\hline Element size & $2 \mathrm{~mm}$ \\
\hline
\end{tabular}

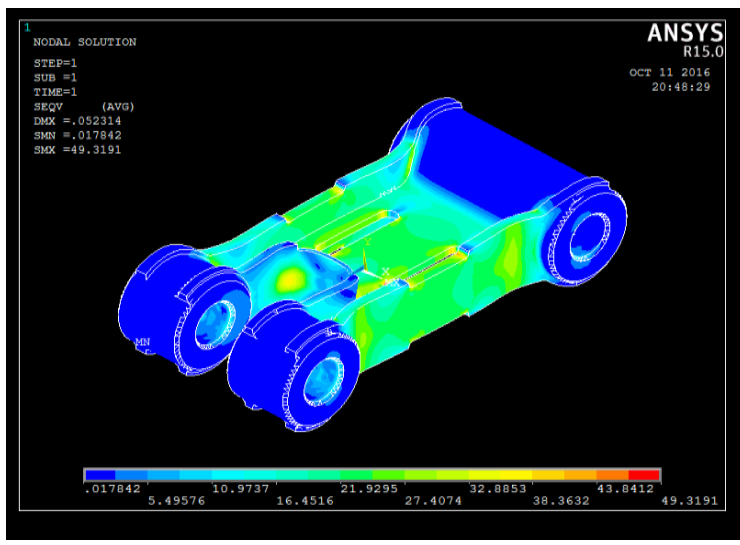

Fig.18: Maximum Principal Stress

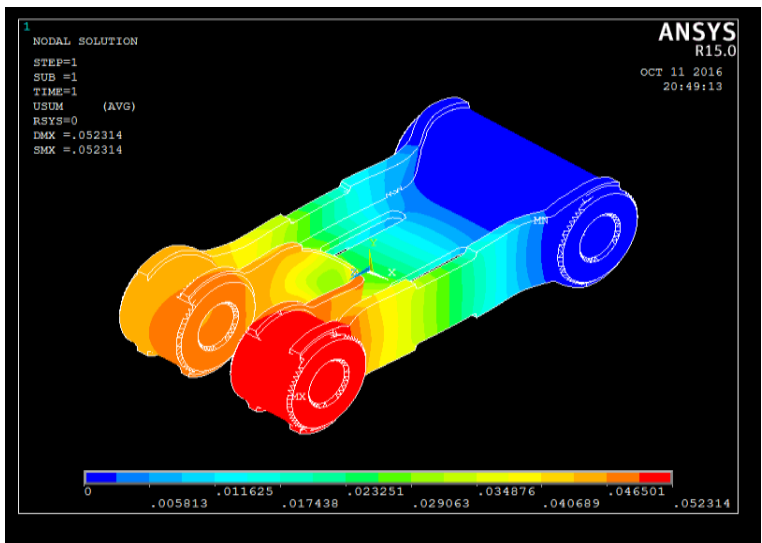

Fig .19: Maximum deformation

Fig. 18 the stress induced in bucket link is $49.31 \mathrm{~N} / \mathrm{mm}^{2}$ which is well below the critical value of $125 \mathrm{~N} / \mathrm{mm}$. Hence, the design is safe and Fig.19 shows the deformation for bucket link is $0.052314 \mathrm{~mm}$. and according to $\mathrm{CAD}$ model as shown in Fig.16 the mass of bucket link is $111.07 \mathrm{Kg}$.

\subsection{Third iteration}

After second iteration, the thickness of side flange of bucket link is reduced to $15 \mathrm{~mm}$ from $20 \mathrm{~mm}$ thickness. As shown in Fig. 20 and Fig.21 shows the CAD model and meshed model of bucket link and the Table 5 shows the details of parameters required for meshing.

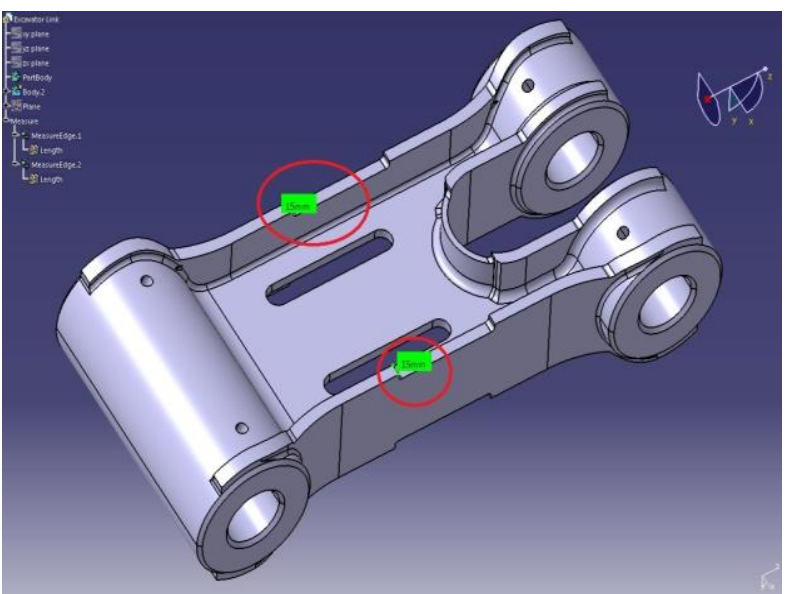

Fig. 20: CAD model of bucket link

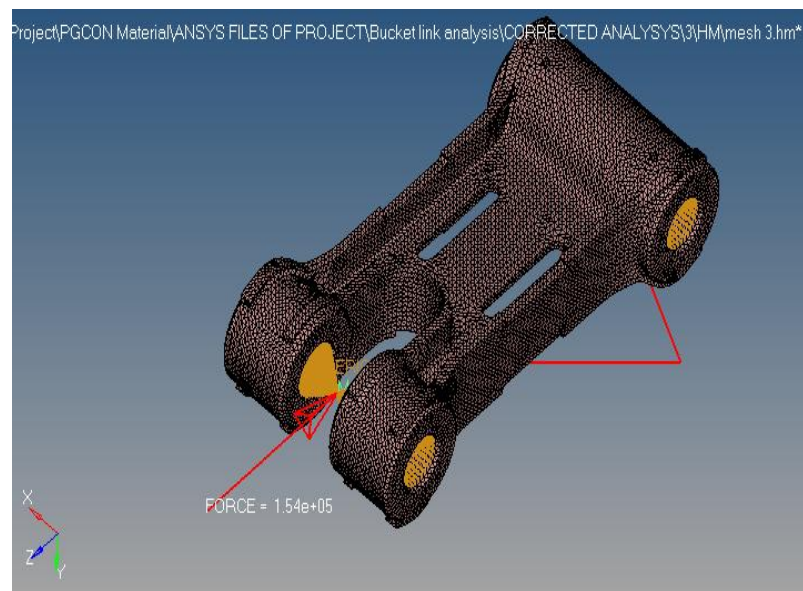

Fig. 21: Meshed model of bucket link for third iteration

Table 5 Meshing parameters for third iteration

\begin{tabular}{|l|l|}
\hline Type of element & Tetra-hedral \\
\hline Number of nodes & 25920 \\
\hline Number of elements & 104179 \\
\hline Element size & $2 \mathrm{~mm}$ \\
\hline
\end{tabular}

Fig. 22 the stress induced in bucket link is $85.60 \mathrm{~N} / \mathrm{mm}^{2}$ which is well below the critical value of $125 \mathrm{~N} / \mathrm{mm}^{2}$. Hence, the design is safe and Fig. 23 shows the deformation for bucket link is $0.226 \mathrm{~mm}$. and according to CAD model as shown in Fig.20 the mass of bucket link is $105.95 \mathrm{Kg}$. 
IOSR Journal of Mechanical and Civil Engineering (IOSR-JMCE)

e-ISSN: 2278-1684,p-ISSN: 2320-334X

PP. 12-26

www.iosrjournals.org

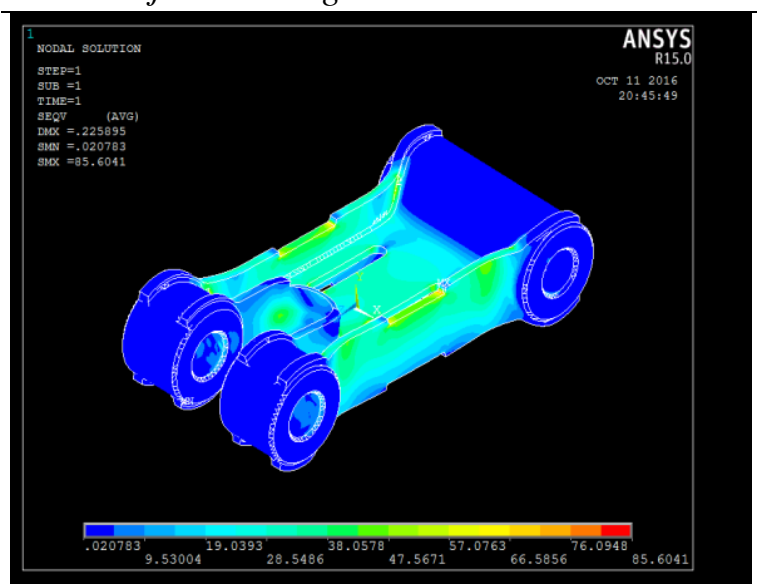

Fig.22: Maximum Principal Stress for optimized bucket link

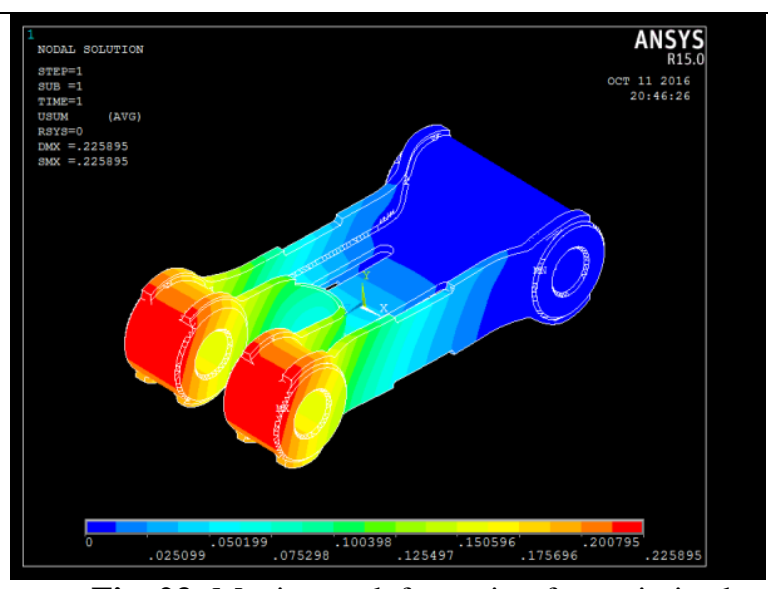

Fig .23: Maximum deformation for optimized bucket link

VI. Determination Of Forces On Scale Down Model Of Excavator Bucket Link

The similitude relation for geometrical parameters, material properties and loadings are derived as shown in Table 6

Table 6 Similitude relations [11]

\begin{tabular}{|l|c|}
\hline \multicolumn{1}{|c|}{ Parameter } & Scale factor \\
\hline Deformation & $\mathrm{S}$ \\
\hline Area & $\mathrm{S}^{2}$ \\
\hline Mass and volume & $\mathrm{S}^{3}$ \\
\hline Deformation & $\mathrm{S}$ \\
\hline Moment of inertia & $\mathrm{S}^{4}$ \\
\hline Density & $\mathrm{SE} / \mathrm{S}$ \\
\hline Point load & $\mathrm{SE} \cdot \mathrm{S}^{2}$ \\
\hline Uniformly distributed load & $\mathrm{SE}$ \\
\hline Stress & $\mathrm{SE}$ \\
\hline
\end{tabular}

The final optimized model of excavator bucket link is scaled down to the ratio of $1: 2$, therefore all the dimensions of optimized bucket link are scaled down to $50 \%$.

Scale factor, $\mathrm{S}=2$

Therefore,

$$
\begin{aligned}
& E_{m}=E_{p}=200 \mathrm{GPa} \\
& S_{E}=1
\end{aligned}
$$

Where,

$S_{E}=$ The ratio of Young's modulus of the prototype to the model.

$\mathrm{S}=$ Geometric scale factor.

The model and prototype denoted by suffix ' $m$ ' and 'p' respectively.

6.1 Similitude relation for deflection of a scaled down model

For a scaled down model, $\mathrm{S}$ is the scale factor. Then the all the dimensions of the prototype should be scaled down by a factor ' $\mathrm{S}$ ',

$$
\text { i.e. } l m=l p / S \text {, }
$$


Where, the geometrical dimensions of the model and prototype are denoted by ' $\mathrm{m}$ ' and ' $l \mathrm{p}$ ' respectively. Therefore,

$$
\begin{array}{rlrl}
\frac{\boldsymbol{u}_{m}}{\boldsymbol{l}_{m}}=\frac{\boldsymbol{u}_{p}}{\boldsymbol{l}_{p}} & \boldsymbol{u}_{m} & =\frac{\boldsymbol{u}_{p}}{\boldsymbol{l}_{p}} \boldsymbol{l}_{m} \\
\boldsymbol{u}_{m}=\frac{\boldsymbol{u}_{p}}{S} & \frac{l_{p}}{l_{m}} & =s \\
u_{m} & =\frac{u_{p}}{2}
\end{array}
$$

The eq. (8) shows that the deformation of scale down model will be ' $\mathrm{S}$ ' (geometric scale factor) times less than the corresponding deformation of the prototype. The deformation in the scaled down model will be $S$ times less than the prototype deformation which is also described in Table 6.

6.2 Similitude relation for load on a scaled down model

In order to maintain same deflection, the load has to be reduced by a factor $S_{E}$. Thus the scale factor for the point load is calculated as $S_{E} S^{2}$,

Where, $S_{E}=1$

$$
\begin{aligned}
&\left(\frac{p}{E l^{2}}\right)_{\text {model }}=\left(\frac{p}{E l^{2}}\right)_{\text {prototype }} \\
&\left(\frac{p_{m}}{E_{m} l_{m}^{2}}\right)=\left(\frac{p_{p}}{E_{p} l_{p}^{2}}\right) \\
& p_{m}=\frac{p_{p}}{S_{E} S^{2}}
\end{aligned}
$$

According to eq. (3), the condition at which mechanism produces the highest breakout force, the load acting on original bucket link (prototype) is,

$$
P_{p}=153.83 \mathrm{KN} \text {. }
$$

The eq. (9) shows that the applied force on scale down model will be $S^{2}$ (square of geometric scale factor) times less than the corresponding load on the prototype.

$$
\begin{aligned}
& p_{m}=\frac{153.83}{2^{2}} \\
& p_{m}=38.45 \mathrm{KN}
\end{aligned}
$$

So, during the experimental testing of scale down bucket link $38.45 \mathrm{KN}$ load will be applied on the scaled model which is $S^{2}$ (square of geometric scale factor) times less than the prototype load described in Table. 6. 6.3 Similitude relation for stress for a scaled down model

The following relation of stresses in model and prototype is formulated to validate experimental stress results with Ansys stress results. The following conditions are valid only when the prototype and the model are of same material.

$$
\begin{aligned}
\left(\frac{\sigma}{E}\right)_{\bmod e l} & =\left(\frac{\sigma}{E}\right)_{\text {prototype }} \\
\sigma_{m} & =\left(\frac{\sigma_{p} E_{m}}{E_{p}}\right) \\
\sigma_{m} & =\frac{\sigma_{p}}{\left(\frac{E_{p}}{E_{m}}\right)} \\
\sigma_{m} & =\frac{\sigma_{p}}{S_{E}}
\end{aligned}
$$

Where, $S_{E}=1$

Therefore, 


$$
(\sigma)_{\mathrm{mod} l}=(\sigma)_{\text {protot }}
$$

According to eq. [10], the stress induced in the scaled model will be same as that of the prototype which is described in Table 6.

6.4 Similitude relation for mass for a scaled down model

The following relation of masses of model and prototype is formulated to validate the mass of manufactured scale down model of bucket link results with optimized bucket linkage.

$$
\begin{aligned}
\left(\frac{m}{v}\right)_{\bmod e l} & =\left(\frac{m}{v}\right)_{\text {prototype }} \quad \text { Because }(\rho)_{\bmod e l}=(\rho)_{\text {prototype }} \\
\frac{m_{m}}{v_{m}} & =\frac{m_{p}}{v_{p}} \\
m_{m} & =\frac{m_{p}}{v_{p} / v_{m}} \quad \text { Where, } \quad \frac{v_{p}}{v_{m}}=S^{3} \\
m_{m} & =\frac{m_{p}}{S^{3}}
\end{aligned}
$$

According to eq.(11), the similitude relation for the mass for the prototype and model the mass of the scaled down model will be $S^{3}$ (cube of geometric scale factor) times less than the prototype mass for same material, According to cad results the mass of optimized bucket link is $105.95 \mathrm{Kg}$.

Therefore,

$$
m_{m}=\frac{105.95}{2^{3}} \quad m_{m}=13.24 \mathrm{Kg}
$$

Therefore, the mass of manufactured bucket link should be $13.24 \mathrm{Kg}$.

6.5 Analysis of scaled down model of excavator bucket link

Fig.24 shows the scaled down model of excavator bucket link with applied boundary conditions.

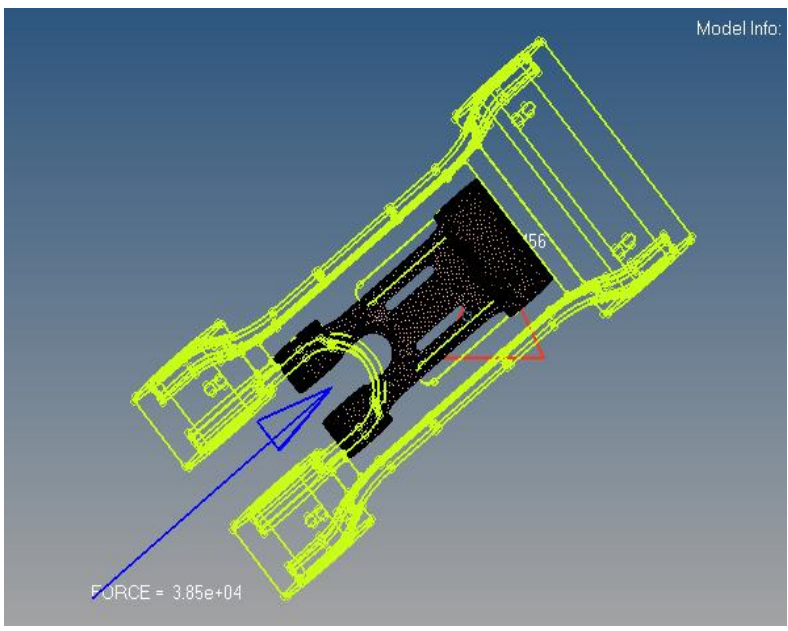

Fig. 24: Meshed model of scale down bucket link

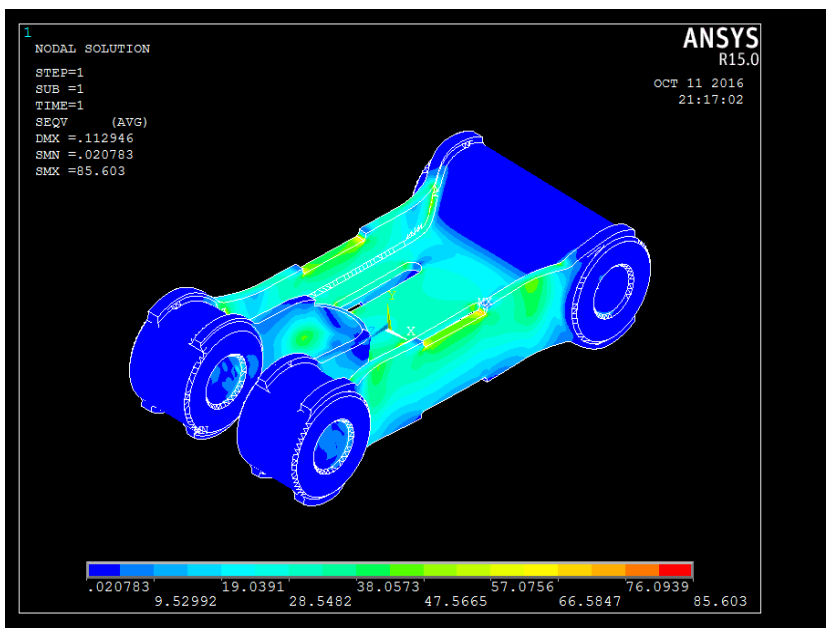

Fig .25: Maximum Principal Stress of scale down bucket link

As shown in Fig.25 and Fig 26, the stress value for scaled down bucket link is $85.60 \mathrm{~N} / \mathrm{mm}^{2}$ and the deformation is $0.1129 \mathrm{~mm}$. According to similitude relations the stress and deformations of scaled down model are validated with experimental results. 


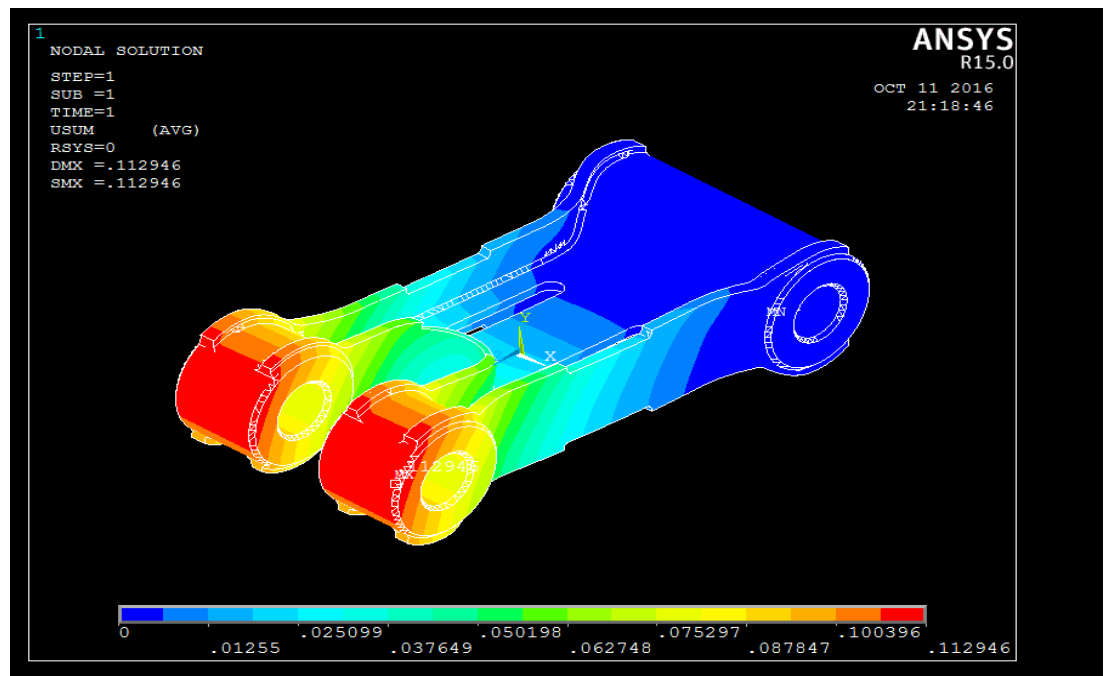

Fig. 26: Deformation of scale down bucket link

\subsection{Experimental setup}

VII. Experimental Analysis Of Excavator Bucket Link

The experimental investigation is performed on manufactured scale down model of bucket link on Universal Testing Machine. The testing has been performed on the manufactured scale down model of excavator bucket link. The input conditions are recreated in the lab while the component is being tested. According to eq. [9], an equivalent maximum load of $38.450 \mathrm{KN}$ is applied on the scale down model for testing purpose.

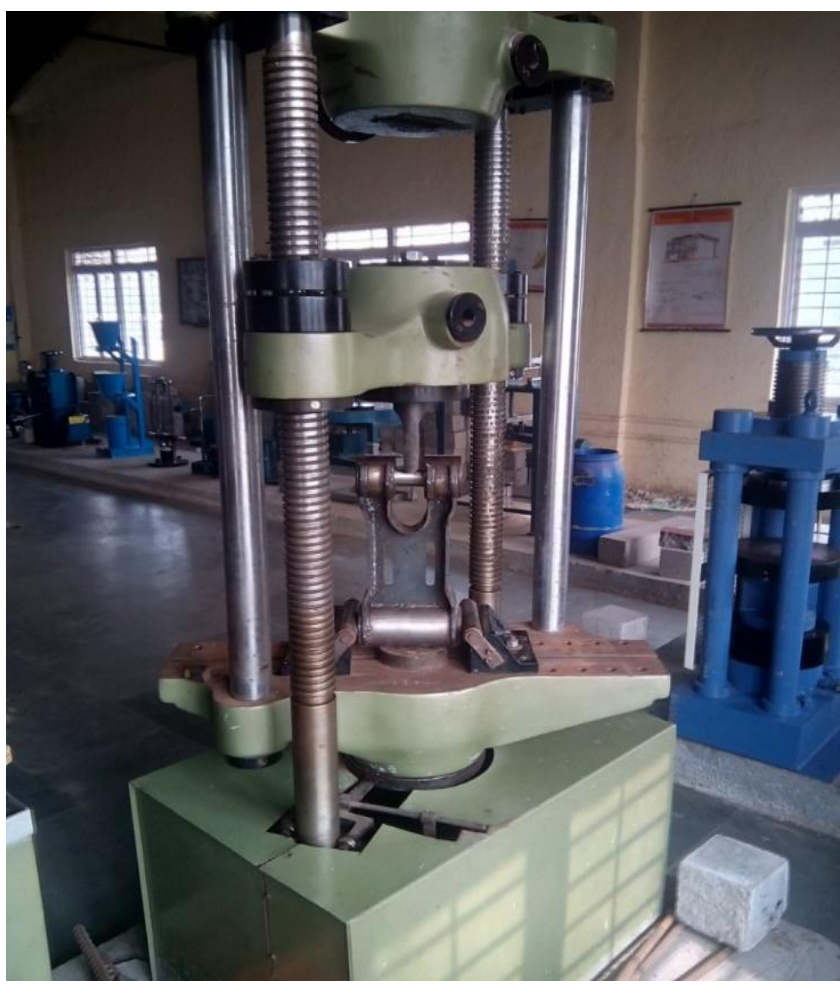

Fig.27: Compression testing on Universal Testing Machine

As shown in Fig 27, the scale down excavator bucket linkage is held in the machine between the grips and the change in gauge length of bucket linkage is automatically recorded by an extensometer during the test. If an extensometer is not connected, the machine itself can not record the deformation between its cross heads on which the bucket linkage is held. However, this method gives the change in length of the bucket linkage. 


\subsection{Experimental testing result}

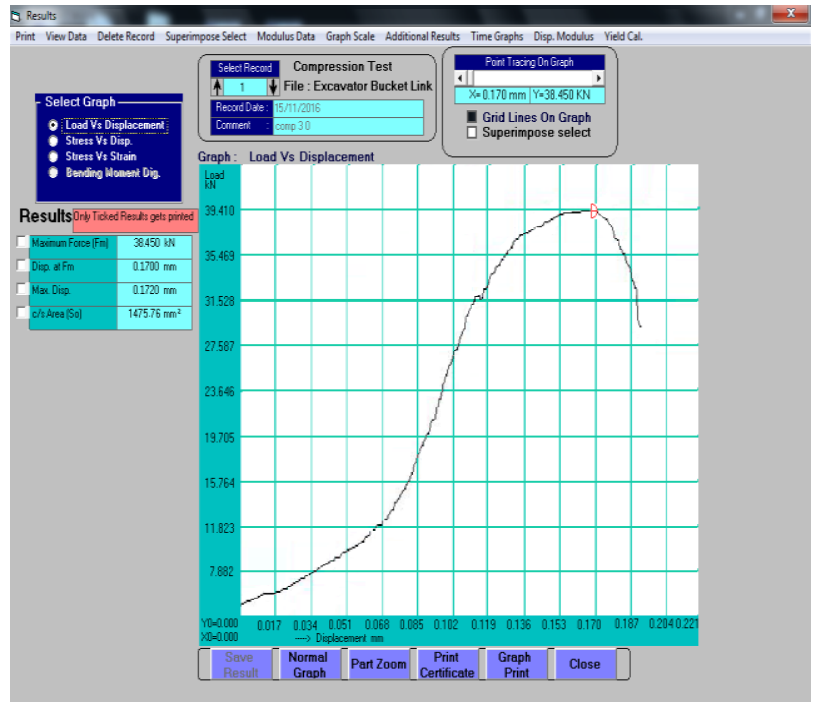

Fig. 28: Load vs. Deformation

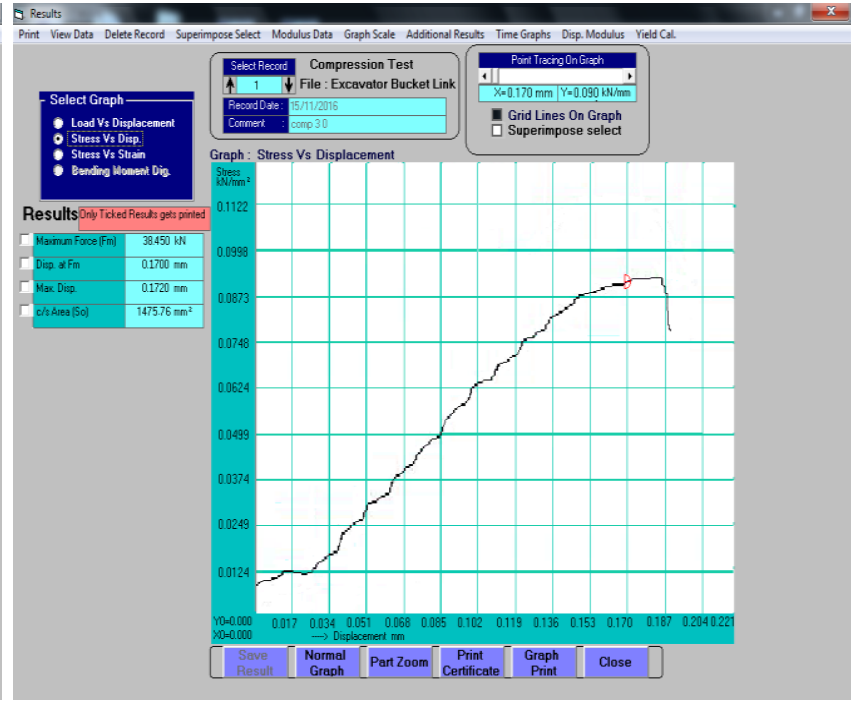

Fig.29: Stress vs. Deformation

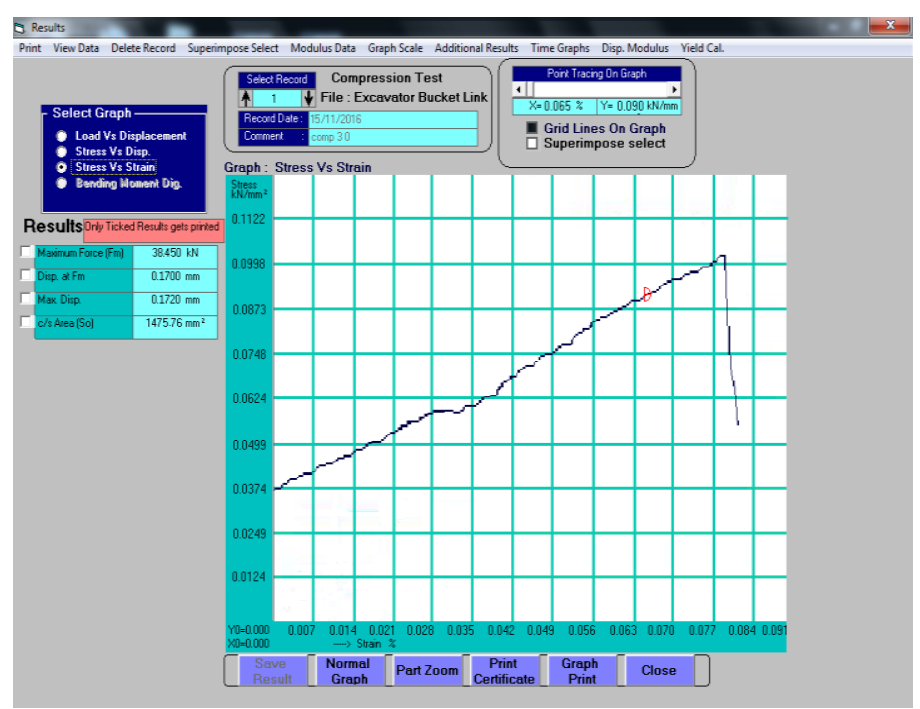

Fig .30: Stress vs. Strain

From Figs. 28, 29, 30, it is seen that the values of stress, strain and deflection of scaled down bucket link of excavator are very good agreement with the numerical analysis. The parameters like deformation, stress and mass of optimized bucket link can be calculated from the experimental values obtained for deformation, stress and mass for scale down model with the help of similitude relations.

\subsection{Similitude relation for deformation}

$$
u_{m}=\frac{u_{p}}{2}
$$

$$
u_{p}=2 u_{m}
$$

The experimental results for deformation of scale down model is obtained as, $u_{m}=0.17 \mathrm{~mm}$.

Therefore,

The deformation of optimized bucket link (prototype) is,

$$
\begin{gathered}
u_{p}=2 \times 0.17 \\
=0.34 \mathrm{~mm}
\end{gathered}
$$




\subsection{Similitude relation for stress}

$$
(\sigma)_{\mathrm{mod} l}=(\sigma)_{\text {protot }}
$$

The experimental results for stresses induced in scale down model is obtained as, $(\sigma)_{\bmod e l}=90.08 \mathrm{MPa}$ Therefore,

The stress induced in optimized bucket link (prototype) is same as that of scaled down model,

$$
(\sigma)_{\text {prototype }}=90.08 \mathrm{MPa}
$$

\subsection{Similitude relation for mass}

The experimental results for mass of scale down model is obtained as, $m_{\mathrm{m}}=13.068 \mathrm{~kg}$

Therefore,

$$
m_{m}=\frac{m_{p}}{S^{3}}
$$

$$
m_{p}=S^{3} \cdot m_{m}
$$

Where, the geometric scale factor, $S=2$,

The mass of optimized bucket link (prototype) is, $\left(m_{p}\right)$

$$
\begin{aligned}
& m_{p}=2^{3} .13 .068 \\
& m_{p}=104.544 \mathrm{~kg}
\end{aligned}
$$

VIII. Results And Discussion

Table 8 Numerical analysis and experimental result of bucket link

\begin{tabular}{|c|c|c|c|c|}
\hline Parameters & $\begin{array}{c}\text { Ansys Result } \\
\text { (Existing } \\
\text { Bucket Link) }\end{array}$ & $\begin{array}{c}\text { Ansys Result } \\
\text { (Optimized } \\
\text { Bucket Link) }\end{array}$ & $\begin{array}{c}\text { Experimental } \\
\text { Result } \\
\text { (Optimized } \\
\text { Bucket Link) }\end{array}$ & $\begin{array}{c}\text { Percentage } \\
\text { Error } \\
(\%)\end{array}$ \\
\hline $\begin{array}{c}\text { Mass }(\mathrm{m}) \\
(\mathrm{Kg})\end{array}$ & 113.285 & 105.95 & 104.544 & 1.028 \\
\hline $\begin{array}{c}\text { Stress }(\sigma) \\
(\mathrm{MPa})\end{array}$ & 32.64 & 85.30 & 90.08 & 5.6 \\
\hline $\begin{array}{c}\text { Deformation }(\boldsymbol{u}) \\
(\mathrm{mm})\end{array}$ & 0.0461 & 0.22 & 0.34 & 12.2 \\
\hline
\end{tabular}

$$
\text { Percentage of wt. reduction }=\frac{\text { Existing weight }- \text { Optimized weight }}{\text { Existing } \text { weight }}
$$

Therefore,

$$
\% \text { weight reduction }=\frac{113.285-105.95}{113.285}=6.47 \%
$$

Total reduction in weight of optimized bucket link $=113.285-105.95=7.34 \mathrm{Kg}$.

\section{Conclusions}

1. The weight reduction of optimized bucket link is $7.34 \mathrm{~kg}$. The percentage of weight reduction is $6.47 \%$ and the stress is $85.30 \mathrm{MPa}$ and these values are within limit.

2. It is observed that, $1.028 \%$ error occurred in the mass, $5.6 \%$ error in the stress and $12.2 \%$ error observed in deformation during experimental and numerical analysis.

3. The stress due to reduction in thickness of flange of the bucket link from $20 \mathrm{~mm}$ to $15 \mathrm{~mm}$ at third iteration is well below the critical value of $125 \mathrm{MPa}$ with factor of safety 2 , hence the optimized design is safe.

4. The experimental value obtained for stress is $90.08 \mathrm{MPa}$ and deflection is $0.34 \mathrm{~mm}$ and it is found very close to Ansys results of stress $85.30 \mathrm{MPa}$ and deformation $0.22 \mathrm{~mm}$.

5. The third iteration gives the sufficient amount of mass reduction without affecting its strength. 


\section{References}

[1] B. Patel, J. Prajapati,Evaluation of Bucket Capacity, Digging Force Calculations and Static Force Analysis of Mini Hydraulic Backhoe Excavator, Machine Design,4,2012, 59-66.

[2] B. Patel, J. Prajapati ,Structural Optimization of Mini Hydraulic Backhoe Excavator Attachment Using FEA Approach,Machine Design,5,2013,46-56.

[3] R. Mishra, V. Dewangan ,Optimization of Component of Excavator Bucket, International Journal of Scientific Research Engineering \& Technology (IJSRET 2(2),2013, 076-078.

[4] S. Mehta, N. Nagare ,Analysis and Optimization of Bucket of an Excavator, 2( 2),2015, 82-92.

[5] G. Mehta, V. Iyer, J. Dave ,Finite Element Analysis and Optimization of an Excavator Attachments, HTC, May 2009.

[6] R. Dhawale, S. Wagh,Finite Element Analysis of Components of Excavator Arm- A Review, International Jouranal of Mechanical Engineering and Robotics Research, 3(2),2014,341-346.

[7] Caterpillar, Catalogue of 320D/D L Series 2 Hydraulic Excavator, May 2015

[8] M. Tupkar, S. Zaveri, Design and Analysis of an Excavator Bucket, IJSRET, 4 (3),2015.

[9] S. Bende, N. Awate, Design, Modeling and Analysis of Excavator Arm,4( 2),2013, 14-20.

[10] S. Chumbale, P. Mahajan ,Failure Analysis and Optimization of Excavator Arm - A Review, IJSRD, 3(2), 2015, 1861-1863.

[11] M. Ramu, V. Raja, P. Thyla ,Analytical and Numerical Validation of Developed Structural Similitude for Elastic Model, Indian Journal of Engineering and Material Sciences,20,2013,492-496.

[12] N. Kim, Y. Kwak, S. Chang, Pseudo-dynamic Tests on Small Scale Steel Models Using the Modified Similitude Law, WCEE,2004.

[13] M. Alves, R. Oshiro, Scaling Impacted Structures When the Prototype and The Model are Made of Different Materials,International Journal of Solids and Structures, 2006.

[14] J. Qureshi, M. Sagar, Study and Analysis of Boom of Backhoe Loader with the Help of FE Tool, IJMER,2(3),2012,882-884

[15] G. Cui, C. Cui, Shape Optimization Based on Ansys" Journal of Information and Computational Science, 3,2015, ISSN: 4291-4297,

[16] R. Marode, A. Bhatkar, Finite Element Analysis of a Backhoe Loader to Study Fatigue Failure, National Conference on Innovative Trends in Science and Engineering, 4(7) ,2016, 163-166.

[17] R. Sarode, S. Sarawade, Structural Optimization of Excavator Bucket Link", IOSR Journal of Mechanical and Civil Engineering, 5, 2016,10-16.

[18] D. Kumar, P. Patel, M. Patel, a Critical Review on Kinematics of Hydraulic Excavator Backhoe Attachment, IJMERR,4(2),2015 188-203. 